\title{
A experiência marginal e o deslocamento nômade em Edward W. Said e Milon Hatoum
}

\author{
Cacio José Ferreira ${ }^{1}$ \\ Norival Bottos Júnior ${ }^{2}$
}

\begin{abstract}
: the objective of this work is to establish, for beyond the dialog between the two intellectuals of Arab origin, a reflection about the way how Milton Hatoum, being quite influenced by the episteme that is usually called "orientalism" thought, seeks to build his characters and nomadic narrators, paradoxically prisoners and in constant process of desterritorialization, and how this desterritorialization creates the problem of aesthetic and political representation in the margins of the Western world, as the case of the Amazon region seems to us. The theme of the displacement is configured as one of the privileged themes of Edward Said and in the case of Milton Hatoum's narrators, it is noticed that the problem of the contemporary intelectual, who must assume the speech of the "other", part of a space occupied by the nomad, since, being foreigners, the narrators present themselves as characters who are always in the "between places", "between cultures" and "between times". To draw the cartography that links nomadic thought of these intellectuals can help us to understand the enigma of a sort of continuous wandering of the narrators and characters of Milton Hatoum's novels. Attachment to the homeland is attachment to emptiness, the narrator becomes naturally the nomad, creating grooves where ruins remains.
\end{abstract}

Keywords: Nomadic; Orientalism; Amazon World; Ruins; Desterritorialization.

Resumo: o objetivo deste trabalho é estabelecer, para além do diálogo entre os dois intelectuais de origem árabe, uma reflexão sobre o modo como Milton Hatoum, tendo sido bastante influenciado pela episteme do chamado pensamento "orientalista", busca construir seus personagens e narradores nômades, paradoxalmente presos e em deslocamento constante, e como essa desterritorialização produz o problema da representação estética e política do mundo nas margens do Ocidente, como nos parece o caso da região amazônica. O tema do deslocamento se configura como um dos temas privilegiados de Edward Said, no caso dos narradores em Milton Hatoum, percebe-se que o problema do intelectual contemporâneo, que deve assumir a fala do "outro", parte de um espaço ocupado pelo nômade, pois, sendo estrangeiros, seus narradores se apresentam como personagens que estão sempre nos "entre lugares", "entre culturas" e "entre tempos". Traçar a cartografia que une o pensamento nômade desses intelectuais pode

1 Professor da Universidade Federal do Amazonas (UFAM).

2 Doutor em Letras - Estudos Literários, pela Universidade Federal de Goiás (UFG). 
ajudar-nos a compreender o enigma de uma espécie de errância contínua dos narradores e personagens nos romances de Milton Hatoum. O apego à terra natal é o apego ao vazio, o narrador torna-se naturalmente nômade, criando ranhuras onde restam ruínas.

Palavras-chave: Nomadismo; Orientalismo; Mundo amazônico; Ruínas; Desterritorialização.

\section{Introdução}

No final do século XIX, a região amazônica foi sacudida inesperadamente de sua atrofia histórica pelo chamado "surto da borracha" e, da noite para o dia a região mais isolada e economicamente atrasada do Brasil, cuja historiografia é ainda hoje escassa, fez com que a capital Manaus se tornasse a segunda cidade mais próspera do país. Torna-se importante então, em poucos traços, delinear em que momento na incipiente historiografia do Amazonas, a região mais oriental do Brasil, passou a ser marcada pelo clima de euforia e pela promessa de um futuro glorioso. Poder-se-ia considerar que o "clima de festa" teve, de fato, início com o período áureo da borracha. O tempo de euforia foi relativamente curto, do final do século dezenove até os primeiros anos do século vinte. O que salta aos olhos é que o resultado deste "surto" de autoconfiança jamais se repetiria na história do país e ainda menos com os resultados que se verificaram após o declínio da extração do látex, o "ouro" amazônico.

As marcas desse período estão presentes até hoje, em certo sentido, nem tudo se perdeu por completo. Não seria exagero considerar que, para além das ruínas que ainda restam daquele período, alguns traços da arquitetura desse passado suntuoso mantém-se de modo razoavelmente bem cuidados, como é o caso de alguns prédios públicos do centro da cidade, poucas praças, o Teatro Amazonas, de renome internacional e que fora construído com material e mão-de-obra vinda da Europa, especialmente da Itália. De resto, a cidade continua seu ciclo de miséria, com um crescimento populacional sem precedentes e sem qualquer controle ambiental.

Entre essa euforia inicial e a última esperança de modernizar a região, a saber, modernizar no sentido de fazer com que o ethos branco finalmente deixassem de ser uma voz vinda de "outro lugar", a região experimentou um novo fracasso, a chamada Zona Franca de Manaus. Caso se julgue importante e em poucos traços delinear em que momento a incipiente historiografia do Amazonas passou a ser marcada pela euforia e pela ideia de que a floresta amazônica seria o novo "Eldorado", poder-se-ia contentar-se em afirmar que o tempo em que durou o ciclo milagroso da extração do látex da borracha e a esperança de modernização já na segunda metade do século, com a instalação da Zona Franca de Manaus, com a abertura da Transamazônica, foram sempre tentativas malogradas de conectar a região ao resto do país, ou seja, uma região que, segundo Márcio Souza (1977, p. 198): “[...] sempre desafiou a tecnologia temperada do Ocidente”. Esses sucessivos fracassos de colonização e neocolonização puderam ser notados mais especificamente a partir dos anos sessenta, a cidade tornou-se um entreposto comercial com várias fábricas multinacionais de aparelhos eletrônicos. Nessa época, também marcada pela forte presença da ditadura militar na região, Manaus passa a “... crescer de maneira irreconciliável com o seu passado" (HATOUM, 2014, p. 264). 
O conjunto da obra ficcional de Milton Hatoum conjuga historicamente esses dois momentos numa verdadeira cartografia do horror, ou dito de outro modo, do fracasso dos estamentos, da burocratização da vida urbana local, da dominação e exploração econômica da floresta, da colonização e escravização da população indígena, por fim, do fracasso de se fazer da região um polo próspero de comércio exploratório.

Muito provavelmente, pode-se afirmar que jamais tenha sido a intenção do autor ou de qualquer outro romancista da região tratar explicitamente do horror da colonização da região amazônica como um tema propriamente, não se pode negar que o horror resultante das sucessivas tentativas de estabelecer um ethos $^{3}$ branco na região gerou sempre um intrincado sistema de relações histórico-sociais que culminaram em fracassos e ruínas.

\section{O nascimento de um ethos oriental no limiar do ocidente}

Pensadores criados nas regiões marginais do mundo, com parece sugerir o caso de Edward Said e Milton Hatoum, tendem a fazer do deslocamento de povos periféricos, do nomadismo causado por problemas sociais e econômicos relacionados à colonização e neocolonização, a própria estrutura de suas narrativas. Para Noemi Campos Freitas Vieira:

Edward Said em suas "Reflexões sobre o exílio" tece observações contundentes sublinhando que o tema do exílio, a despeito do horror e da violência que verdadeiramente representam para a humanidade, [...] tem servido de mote para a proliferação de grande parte da produção literária do século XX . (VIEIRA, 2007, p. 136)

A literatura pós-colonial seria, partindo dessa perspectiva, uma narrativa do espólio. Tratando dos problemas dos deslocamentos, do não-pertencimento, do tema da imigração, esses intelectuais estabelecem um espaço intervalar, um "entre lugar" físico e existencial como condição primordial para a existência e resistência de uma hermenêutica que poderíamos denominar, segundo as palavras de Gilles Deleuze, de deslocamento nômade:

Esta é uma distribuição de errância e até mesmo de "delí-rio", em que as coisas se desdobram sobre toda a extensão de um Ser unívoco e não dividido. Não é o ser que se divide segundo as exigências da representação, mas todas as coisas que se dividem nele na univocidade da simples presença" (DELEUZE, 2012, p. 54). "O que caracteriza o deslocamento nômade é que toda a matéria é colocada do lado do conteúdo, enquanto toda forma passa para o lado da expressão. Parece que a existência nômade é imediatamente mais sensível à conexão do conteúdo e da expressão por si mesmos, cada um desses dois termos tendo forma e matéria. É assim que para a ciência nômade a matéria nunca é uma matéria preparada, portanto, homogeneizada, mas é essencialmente portadora de singularidades (que constituem uma forma de conteúdo). E a expressão tampouco é formal, mas inseparável de traços pertinentes (que constituem uma matéria de expressão). É um esquema inteiramente outro, [...] já que podemos fazer uma ideia dessa situação se pensarmos no caráter mais geral da arte nômade, onde a conexão dinâmica do suporte e do ornamento substitui a dialética matéria-forma. Assim, do ponto de vista dessa ciência que se apresenta tanto como arte quanto técnica, a dimensão do trabalho existe plenamente, mas não adota a dualidade forma-matéria (mesmo nas correspondências biunívocas). Ela antes segue as conexões en-

3 (Grifo nosso) 
tre singularidades de matérias e traços de expressão, e se estabelece no nível dessas conexões, naturais ou forçadas. É uma outra organização de trabalho e do campo social através do trabalho. (DELEUZE \& GUATTARI, 2011, p. 37-38)

O ponto de partida deste trabalho busca, então, privilegiar o espaço outorgado à figura do intelectual do século vinte como figura marcadamente diaspórica. São intelectuais inscritos em regiões ditas "marginais" que, mesmo vivendo em grandes centros urbanos do Primeiro-Mundo, seu traço marcante, de todo modo, seria o efeito indissociável de experiências coletivas que sofreram a influência dos sucessivos processos de colonização ocidental.

A tarefa desses intelectuais em constante deslocamento se constituiria, segundo Pierre Bourdieu (1989, p. 23), no campo de tomadas de posições e na construção de epistemologias capazes de dar conta das múltiplas e complexas dinâmicas político-sociais do mundo fragmentado da contemporaneidade. É nesse sentido que se busca tratar inicialmente dos diálogos-traduções entre o pensamento desses dois intelectuais de ascendência libanesa, formados igualmente pela experiência de um saber às margens do Ocidente: o filósofo Edward Said e a influência de seu pensamento sobre o mundo ficcional de Milton Hatoum.

Há alguns dados biográficos de Milton Hatoum que podem ser imediatamente relacionados a seu vínculo com o Oriente e, principalmente, com a teoria desenvolvida por Edward Said a respeito das aporias relacionadas ao modo como o Oriente seria uma criação do Ocidente ${ }^{4}$ como forma de reconhecer esse novo território como um espaço exótico e distópico do Ocidente. Considera-se, assim, importante manter presentes algumas informações a respeito do problema de "quem fala", sob a condição de não procurar aplicar ou adequar essas informações à interpretação do romance que não se confunda com a ideia de explicar a obra pela biografia do autor. Nesse contexto, não pretendemos, ao apresentar esses dados, examinar ou imaginar supostos sentimentos, intenções que estariam ligados aos modos de subjetivação do escritor em relação às obras.

Essas observações biográficas são feitas no sentido de apontar o lugar de partida dos romances. A primeira dessas informações biográficas consiste na ascendência árabe de Milton Hatoum

Antes de mais nada, a noção de pátria está relacionada com a língua e também com a infância. O que mais marca na vida de um escritor, talvez seja a paisagem da infância e a língua que ele fala.

Eu me lembro - a propósito do dilema: falar árabe ou falar português - de que minha mãe

4 Segundo o próprio Milton Hatoum: O Orientalismo, livro de Edward Said, foi uma das leituras mais importantes sobre essa questão da construção imaginária do discurso sobre o outro oriental, sobretudo sobre o mundo islâmico. O Orientalismo é um dos ensaios seminais sobre as relações entre o Oriente e o Ocidente, sendo que o Oriente, como Said mostrou, é uma construção, é uma invenção do Ocidente. É um tipo de representação que o discurso orientalista teceu ao longo da história, sobretudo a partir do século XVIII. Pode ser que haja, inconscientemente, uma influência do Edward Said no título. A verdade é que foi difícil encontrar este título. Para mim foi um achado. Eu já havia praticamente terminado o romance e tinha outros títulos em mente, como "Retratos da memória". Eu lembro que esse era um dos títulos possíveis, mas gostei desse título Relato de um certo oriente, porque nele há várias perguntas. De que Oriente nós estamos falando? De um determinado Oriente? Mas qual deles? É isso que o livro insinua. É o mistério em torno desse Oriente que está um pouco nebuloso, e ainda não se sabe qual é o Oriente do romance. Entrevista concedida a Maged T.M.A.El Gebaly. 2010. Revista Crioula, ${ }^{\circ}$ 7. Disponível em: https://www.revistas.usp.br/crioula/ article/viewFile/55258/58887. Data de acesso: 13/08/2015. 
dizia que eu deveria falar português, porque a língua é a pátria. A brasilidade está presente na língua, mas não sei até que ponto está presente numa paisagem brasileira: porque não sei se se pode definir exatamente "paisagem brasileira" para quem é da Amazônia. A Amazônia não tem fronteiras; sim há uma delimitação de "fronteiras", mas para nós não passam de fronteiras imaginárias. Que importa, para os índios yanomamis, por exemplo, se eles foram assassinados na Venezuela ou no lado brasileiro? Para os índios, o território, a terra deles não tem fronteiras...

E para todos nós, nascidos na Amazônia, a noção de terra sem fronteiras está muito presente... Porque é um horizonte vastíssimo, em que as línguas portuguesa e espanhola se interpenetram em algumas regiões, onde as nações indígenas também são bilíngues, às vezes poliglotas (índios que falam tucano, espanhol, português (...). Há um mosaico de grandes nações, de tribos dispersas; na verdade, cada vez mais dispersas...

Uma dessas pequenas tribos dispersas é a dos orientais; dos imigrantes que chegaram no início do século e que participaram da vida econômica da região. Aliás, os primeiros imigrantes foram para o Acre, para uma terra que não era ainda brasileira. Eu tenho pesquisado documentos sobre a Revolução Acreana e notei que alguns oficiais do exército brasileiro que combateram pela independência do Acre são de origem libanesa: há um Capitão Alexandre Farhat, um Cel. João Turco, personagens que pertencem à história do Acre e estão já presentes também na historiografia. (HANANIA, 2001, s/p)

Neto de libaneses, Milton Hatoum viveu em Manaus até os 15 anos. Seus primeiros anos longe da terra natal foram em Brasília, entre 1968 e 1969, anos conturbados do golpe militar. Em seguida, mudou para São Paulo, formou-se em arquitetura e partiu para uma temporada na Europa, vivendo em Barcelona, Madri e Paris, só retornando a Manaus em 1984, quando passou a lecionar Literatura Francesa na Universidade Federal do Amazonas - UFAM. Em 1999, após quase vinte anos decide se mudar para São Paulo e vive lá desde então. Há breves passagens do autor amazonense por universidades norte-americanas na condição de escritor-residente nas universidades de Yale, Stanford e Berkeley.

O que é interessante notar nesse breve resumo biográfico é o modo como Milton Hatoum pode ser identificado como o típico pensador pós-colonial, ou seja, o intelectual que não apenas opera a força de seu pensamento partindo da noção de que há na história do pensamento uma margem, ou mesmo um espaço circunscrito à relação com um "fora", como também o caráter híbrido que essa noção implica dentro de uma hermenêutica da contemporaneidade, noção que Jacques Derrida chama de gramatologia:

É a tentativa de apreender um sistema de pensamento sempre aberto, (...) e por essa razão, necessita de uma arquitetura estratégica, para fugir da economia conceitual tradicional da filosofia, que sempre levaria o pensamento de um filósofo a fechar-se em torno de seu próprio sistema. (...) Derrida, sem poder abrir mão totalmente de conceitos, direciona suas forças em cunhar o que viria a chamar de "indecidíveis", ou "quase conceitos", ou seja, termos que não carregam em si nenhuma definição precisa, definitiva, mas que funcionam numa cadeia de remetimentos, do mesmo modo como funcionam os conceitos. (...) Conceitos que não conceituam; que não pretendem dar conta de um sentido ou de um significado fechado e que, por isso, inauguram uma nova forma de relação entre as palavras e as coisas. E é assim que surge a ideia da desconstrução, um gesto que pretende mostrar a violência autoritária de um sistema fechado que se apresenta como a única maneira de compreensão do real e não se mostra, de maneira alguma, como mais uma construção na História das Construções (ou fábulas, como dizia Nietzsche) que é a história da filosofia. (HADDOCK-LOBO, 2014, p. 26) 
O oriental, como bem salientou o próprio autor a respeito do que significa ser árabe, libanês-brasileiro, numa região afastada do próprio Brasil, e em que as típicas noções arcaizantes de território, de nacionalidade e de espaço acabam se tornando, além de problemáticas, insuficientes. O Amazonas, ou o Norte, seria então como um território oriental dentro do espaço subalterno do Brasil como parte geográfica do Ocidente.

Milton Hatoum parece sugerir, desde o início de sua produção literária, que há em sua formação a profunda consciência e a consequente preocupação em questionar certos paradigmas arcaizantes e conjuntos de classificação binários. E esse é o mesmo caminho traçado por Edward Said em seu projeto acadêmico. É preciso ressaltar, no entanto, que não se trata, por parte do escritor amazonense, de uma tentativa de apropriação teórica para uso de uma prática literária ou artística. Trata-se, na verdade, não apenas de uma aproximação teórica e ontológica, mas, sobretudo, de uma continuação da ideia postulada por Edward Said a respeito dos povos marginalizados do mundo.

O empreendimento teórico também é habitualmente denominado de Estudos Pós-Coloniais e pode ser visto como o elemento mais importante que liga o trabalho acadêmico de Edward Said ao conjunto da obra ficcional de Milton Hatoum mapeado neste capítulo, uma cartografia que funcionaria segundo os termos de uma agenda intelectual em comum. Em ambos percebe-se a ênfase na pluralidade e na desconstrução dos saberes institucionalizados, tanto no projeto teórico de Edward W. Said quanto na prosa de Milton Hatoum nota-se o predomínio da metalinguagem e da intertextualidade. É preciso, no entanto, considerar que a questão da burocracia e letargia estamental, da natureza e da estrutura da noção de Terceiro Mundo, ou mesmo da relação marginal da região amazônica como margem do Ocidente é mais problemático do que uma simples questão de isolamento territorial ou falta de um projeto político sustentável para a região.

A primeira questão a ser abordada é se, de fato, as preocupações em relação ao chamado Terceiro Mundo sempre devem ser vistas em termos de colonialismo. Edward Said leva essa questão em consideração tentando descobrir em como o chamado "orientalismo alemão" poderia se parecer em grande medida com o orientalismo inglês ou francês, embora a historiografia nos mostre que os alemães não tiveram, propriamente, interesses coloniais no Oriente Médio. Mas Edward Said concentra-se nessa questão como ponto de partida para um empreendimento teórico mais amplo, capaz de englobar a noção de orientalismo a todas as regiões colonizadas pelo Ocidente.

A resposta de Edward Said é que o orientalismo alemão não poderia ser outra coisa que um produto de derivação, em termos acadêmicos, do orientalismo francês. E que sua tarefa reduzir-se-ia em manter as características desse pensamento e refletir, por postergação, a partir do prisma do conjunto epistemológico francês sobre o que seria, então, catalogado como o Oriente. Trata-se, então, do mesmo pensamento, porém, derivado.

É nesse momento que o filósofo e professor de literatura de origem palestina volta-se para os interesses da Companhia Britânica das Índias Orientais ${ }^{5}$, que pode ser vista tanto como um empreendimento do programa nacionalista quanto globalizante ${ }^{6}$. Porém, uma confusão que aparece na história mais recente do colonialismo é o problema das verdadeiras motivações do colonialismo. Seria sempre o nacionalismo, ou como parece ser cada

5 É preciso ter em vista que essa companhia inglesa de navegação comercial citada acima exercerá importante papel no processo de colonização da região amazônica, como veremos na análise dos romances de Milton Hatoum, especialmente em Órfãos do eldorado (2008) [N.A].

6 (RIBEIRO, 2007). 
vez mais interessante pensar que a motivação e o modo de agir dos povos colonizadores tinham e ainda mantém valores transnacionais de produção em larga escala, é interessante notar que nas narrativas de Milton Hatoum a Companhia das Índias Ocidentais aparece como uma "marca" da ruína de famílias de fazendeiros colonizadores que enriqueceram com o comércio da borracha. A relação entre o colonizador e o colonizado seria, dessa perspectiva, um tipo de conexão de uma nação metropolitana e suas províncias. Não se trata de desmerecer a importância do nacionalismo como componente fundamental no processo de colonização porque, na verdade, o nacionalismo parece reaparecer com mais intensidade na contemporaneidade.

O que os dois autores defendem é que, similar ao conceito de loucura elaborado por Michel Foucault (2012), que via na experiência da loucura um conjunto de saberes que não podiam ser transmitidos, haveria, também, para o conceito de orientalismo uma série de "saberes outros", desordenados ou deixados à margem do pensamento sobre o assunto e que estão muito longe de se configurar simplesmente como compartimentos e categorias estanques e ordenadas como um arquivo.

Esta seria, de certo modo, a principal preocupação de Edward Said a respeito dos povos do Oriente Médio: evidenciar o modo como o termo "orientalismo" fora utilizado para dizer não o que seria efetivamente o Oriente, mas, sobretudo, o que ele não poderia ser de modo algum, principalmente se a perspectiva adotada fosse a mesma daquele que detém o direito à fala.

Também há outro fator, o poder do discurso criado sobre o Oriente, a saber, todo o material extensamente produzido e catalogado pelo Ocidente sobre esses "outros povos" que, de um modo quase obsessivo, permaneceram no imaginário do Ocidente e passaram, em algum momento, a ser construídos pelo discurso do Ocidente numa variedade quase infinita que não tinha como fundamento apenas o controle político e econômico, mas havia toda uma ampla rede de interesses que passava, quase que invariavelmente, pela dominação cultural:

Tomando o final do século XVIII como um ponto de partida muito grosseiramente definido, o orientalismo pode ser discutido e analisado como a instituição organizada para negociar com o Oriente _negociar com ele fazendo declarações a seu respeito, autorizando opiniões sobre ele, descrevendo-o, colonizando-o, governando-o: em resumo, o orientalismo como um estilo ocidental para dominar, reestruturar e ter autoridade sobre o Oriente. (...) A minha alegação é que, sem examinar o orientalismo como um discurso, não se pode entender a disciplina enormemente sistemática por meio da qual a cultura europeia conseguiu administrar, _e até produzir_o Oriente política, sociológica, ideológica, científica e imaginativamente durante o período pós-Iluminista. (SAID, 1996, p. 15)

Nesse sentido, tanto Edward Said quanto o escritor amazonense, Milton Hatoum, constituem uma espécie de sequência subterrânea dessa ampla rede discursiva que gira a respeito do que seria uma ideia capaz de redimir a tragédia da colonização. Edward Said ocupar-se-ia, assim, de como o Ocidente cria uma representação convincente do que seria o Oriente. Milton Hatoum, na esteira de Edward Said, busca refletir estética e politicamente, em nome de uma escritura da diferença e em nome da desconstrução dos modelos ocidentais. O intelectual que busca refletir a partir desse "fora" teria também o papel de trazer à tona um conjunto de memórias que tenderiam naturalmente a desaparecer em nome do silêncio ancestral que impera sobre as vozes do passado. 
A ideia da ruína, para escritores pós-coloniais, pode ser entendida como uma maneira de se relacionar com um tema que, desde o momento em que passou a ser marcado por uma inscrição, por uma determinada organização, passou a operar como um apagamento, uma exclusão, um silenciamento tanto do que foi dito como daquilo que jamais poderia ser expresso em qualquer época, ou seja, haveria uma consciência por parte do autor pós-colonial acerca de sua relação de inclusão e de exclusão pela escrita.

O tema da inclusão do silêncio, por exemplo, tão marcante na escritura de Milton Hatoum traria, desde o início, a busca pela escritura a partir de sua posição de que é possível ao colonizado assumir a autoria de seu discurso. Em Cinzas do Norte (2012), os diários escritos por Ranulfo, tio do narrador Lavo e amante de Alicia, mãe do protagonista Mundo, parecem evocar um itinerário da recuperação de um fato enquanto recapitulação, reparando a ordem inviolada ou imperfeita de uma temporalidade silenciosa e misteriosa, como neste trecho de uma carta de Ranulfo, endereçada ao personagem chamado Mundo. O tema é a origem desconhecida da família de Alicia, provavelmente trazida de algum lugar do Alto Solimões a Manaus:

\begin{abstract}
Algiza e Ozélia [mãe e irmã de Alicia] não se davam com ninguém, se entendiam por meio de gestos, e os novos moradores do bairro pensavam que elas eram surdas-mudas; sentadas na rua de terra, tomavam caiçuma de abacaxi na mesma cuia e depois iam, juntas, ver o rio e a cidade no fim da tarde; voltavam para casa ao anoitecer e se embrenhavam no castanhal para apanhar pedaços de madeira. Não iam aos arraiais da igreja nem às festas de São João, e se não fosse a ajuda do meu cunhado, não sei como conseguiriam comida e roupa. Tua mãe convidava Algiza para passear no porto ou conhecer outros bairros; ela nunca ia, e só abria a boca para dizer: 'Espero a visita do nosso pai'. (HATOUM, 2012, p. 137)
\end{abstract}

Em suas obras, Milton Hatoum não ignora a posição do colonizador em conflito com a figura do colonizado, porque vê as duas como sendo radicalmente interligadas, mas ao mesmo tempo é possível notar seu interesse nas variadas formas de falar que constituem esse complexo jogo de sobrevivência de saberes e de tradições do colonizado, em seu processo de hibridização com o discurso do colonizador. Nesse processo, a narrativa ganha um espaço estratégico, pois, ao escutar, olhar e observar, a narrativa de ficção busca compreender um determinado complexo imagético através do ato de criação como ato de potência.

Para a ficção, é necessário pensar na escolha das imagens e também na sua materialização, ou seja, a maneira como se expõem determinados fatos a partir do tom dado a essas imagens, como na novela Órfãos do eldorado (2008), cujo narrador, Arminto Cordovil, conta não apenas seu caso de amor pela misteriosa índia Dinaura, mas também a modulação que ele utiliza para falar da fauna local e dos nomes indígenas.

Vê-se nesse processo de hibridização cultural um complexo jogo em que a tradição cultural torna-se efetivamente uma rede de fluxos rizomáticos, pois o conhecimento das tradições não pertencem mais apenas ao mundo do colonizador, mas antes, um amplo comércio cultural sem raízes definidas - Arminto Cordovil é neto de colonizadores portugueses. O que resta nesse processo de hibridização parece-nos configurar-se na problemática relação da memória como representação visual do passado e o estatuto ontológico dessas imagens como resultado dessa operação. A divisão entre os limites do que pode o colonizado falar é implodida a partir de dentro do próprio discurso do colonizador, como no trecho abaixo: 
Quando olho o Amazonas, a memória dispara, uma voz sai da minha boca, e só paro de falar na hora que a ave graúda canta. Macucauá vai aparecer mais tarde, penas cinzentas, cor do céu quando escurece. Canta, dando adeus à claridade. Aí fico calado, e deixo a noite entrar na vida. (HATOUM, 2008, p. 14)

Há outra aproximação necessária entre esses dois intelectuais das margens do globo. $\mathrm{O}$ orientalismo de Edward Said posiciona-se muito bem no momento histórico que busca colocar entre parênteses a efetividade dos binarismos recorrentes na tradição estruturalista. Não parece haver a interdependência mútua do modelo binário do indivíduo centrado em si e de um "outro" descentralizado, incluindo o modo como a construção da alteridade do outro é, na verdade, e secretamente, ao mesmo tempo um meio de construir, de definir e delimitar a natureza da individualidade, o "ser" ocidental ou oriental. O que se pode notar é que há, em especial nos dois primeiros romances de Milton Hatoum, a saber, Relato de um certo Oriente e Dois irmãos e o conjunto da obra de Edward Said uma preocupação em desconstruir o pensamento tradicional entre oposições binárias e imutáveis. É neste sentido que Daniela Birman busca,

Sugerir que Hatoum explora e brinca no Relato -procedimento ao qual dará prosseguimento em Dois Irmãos - com a diferenciação e separação entre Oriente e Ocidente que marca os textos nomeados por Edward Said de orientalistas. Esta distinção foi incorporada ao nosso olhar, discurso e conhecimento sobre esse imenso território que constituímos como nosso Outro - e cuja oposição a nós está, portanto, na base de nossa "identidade ocidental. (BIRMAN, 2007, p. 25-26, grifos da autora)

O olhar eivado pela consciência da existência de um discurso sobre o território do "outro" é uma marca bastante presente na literatura de Milton Hatoum, que se apropria dessa figura desconstruída por Edward W. Said, ou seja, a do "oriental", e a traduz em termos literários, demonstrando, a seu modo, que as diferenças não são construções naturais, mas antes, deixadas como rastro de uma construção cultural dominante sobre outra, oculta, silenciada e destinada ao esquecimento. $\mathrm{O}$ sentido que ambos dão ao ponto de vista do "oriental" sobre os "outros", os ocidentais, busca refletir sobre a maneira como essas relações decompõem-se e, num sentido redobrado, identifica uma consciência dupla, para que não se distinga claramente o colonizador e o colonizado como uma oposição binária. Nesse sentido, Milton Hatoum relata

Eu apreciava alguns escritores europeus que, sintonizados com o renascimento oriental, escreveram obras que valorizam a cultura "excêntrica", em oposição a uma cultura que se pretende mais complexa e artificial, produzida no "centro", na Europa. Nossas peregrinações ao Oriente procuravam às vezes uma outra pátria, ou um lugar ideal para o sonho e o devaneio, como alguém que busca na paisagem estrangeira o avesso da casa em que habita. Para Gerard Nerval, o Egito é um país de mistérios e enigmas [...]. Outras vezes esses escritores se armam de um projeto etnocêntrico, em que a glória pessoal de uma descoberta geográfica se mescla aos serviços prestados à pátria. $\mathrm{O}$ projeto literário serve ao expansionismo colonial. [...] Diante de textos tão díspares, fiz como um leitor que pratica um ritual de canibalismo literário, assimila o que lhe dá prazer. Com isso, quero dizer que a literatura árabe foi tão importante quanto os textos orientalistas, e esse duplo interesse residia sobretudo no encanto da linguagem, como nos contos de As Mil e Uma Noites ou na Viagem ao Oriente, de Nerval. (HATOUM, 1991, p. 12) 
Alguns outros autores já identificaram a intensidade do diálogo e da influência que o escritor amazonense estabelece com o trabalho de Edward Said, como Lourival Cury, em sua análise do romance Dois irmãos:

No romance que analisamos, o narrador assume também a figura do intelectual. Nael torna-se professor. Deve-se assinalar que Milton Hatoum foi tradutor de algumas obras de Edward Said, o pensador contemporâneo que desenvolveu uma muito aguda reflexão sobre a função do intelectual, ao qual atribui um papel político no nosso mundo dominado por divisões e intolerância. É necessário lembrar que a autobiografia de Edward Said tem como título Out of Place, livro em que, como em outras publicações, desenvolve a ideia de que o intelectual deve falar a partir da margem da produção das ideias, evitando o pensamento central e levando em conta os marginalizados do conjunto social. A condição do intelectual é a do exílio, a do "fora-do-lugar", deslocando a frente da cena. Ocupar este lugar é igualmente o papel do narrador do romance de Milton Hatoum _o inominado, o bastardo, o ilegítimo,_simultaneamente engajado e distanciado, deslocado, mediador de seu próprio discurso e do discurso alheio, criando lugar à margem. (CURY, 2009, p.49, grifos do autor).

Para Homi Bhabha o Oriente ou mesmo um entreposto oriental na região amazônica representam o lugar privilegiado de contestação dos valores sócio-culturais dominantes - lembremos que o título do primeiro romance de Milton Hatoum é Relato de um certo Oriente (2014) - e já nesse primeiro romance uma profusão de vozes marginais e dissonantes entra em cena, buscando renegociar seus espaços de enunciação.

Mas a importância das teses de Edward Said na produção ficcional de Milton Hatoum pode ser identificada, sobretudo, no esclarecimento de certas noções aporéticas em torno do termo orientalismo, através do qual o Ocidente não apenas buscou representar o "outro" a partir de suas próprias crenças naquilo que o outro deveria ser, mas também um:

[...] modo de resolver o Oriente que está baseado no lugar especial ocupado pelo Oriente na experiência ocidental europeia.O Oriente não está apenas adjacente à Europa; é também onde estão localizadas as maiores, mais ricas e mais antigas colônias europeias, a fonte das suas civilizações e línguas, seu concorrente cultural e uma das suas mais profundas e recorrentes imagens do Outro. [...] Contudo, nada desse Oriente é meramente imaginativo. O Oriente é parte integrante da civilização e da cultura materiais da Europa. [...] O orientalismo é um estilo de pensamento baseado em uma distinção ontológica e epistemológica feita entre "o Oriente" e (a maior parte do tempo) "o Ocidente". Desse modo, uma enorme massa de escritores, entre os quais estão poetas, romancistas, filósofos, teóricos políticos, economistas e administradores imperiais, aceitou a distinção básica entre o Oriente e o Ocidente como o ponto de partida para elaborar teorias, épicos, romances, descrições sociais e relatos políticos a respeito do Oriente, dos seus povos, costumes, "mente", destino e assim por diante. (SAID, 1996, p. 14, grifo do autor)

Nesse caso, o Amazonas também seria uma espécie de Oriente. Parece-nos importante notar, de antemão, como o espaço amazônico constitui-se num caso único no processo de colonização no Brasil. É o que nos atesta Márcio Souza, outro grande romancista amazonense:

A Amazônia morre pelos pecados dos brancos. Há 300 anos foi estabelecido um conflito que ameaça a integridade do grande vale. Um conflito que sentimos na pele e que se revela 
diariamente nas ruas de nossas cidades, nas estradas que abrem o caminho do desmatamento. E nestes longos anos de conflito, nossa expressão artística parece recusar-se a reconhecer o perigo. Movidos pelas necessidades econômicas da empresa colonial, instigados pela ideologia da contrarreforma, os portugueses nos ensinaram a ver naquilo que há de mais originário, um inimigo desprezível. Sistematicamente banida de nossa investigação artística, a cultura mais autêntica e viva da região recolheu-se para os arquivos etnográficos. $\mathrm{O}$ que era para ser esteio, viga-mestra e estrada luminosa, tornou-se curiosidade e folclore para especialistas. Poucos foram os que vislumbraram esse universo, a maioria preferiu a rota confortável do aniquilamento pela importação desenfreada de estéticas alienantes. A Amazônia índia é um anátema, um purgatório onde culturas inteiras se esfacelam no silêncio e no esquecimento. E quando essa entidade heroica e sofredora deixar de existir, será necessário encontrar outro nome para o vale: já não mais teremos a Amazônia. Mas a Amazônia é paciente, ela já viveu milênios. Para os índios, que sofrem e morrem esses 300 anos de presença "civilizada", isso não é mais que alguns séculos no grande tempo dos milênios. Outras ameaças já atravessaram seus caminhos, se bem que nenhum tivesse o cristianismo e bombas de napalm. (SOUZA, 1977, p. 28-29)

O esfacelamento a que Márcio Souza se refere também pode ser aplicado às culturas hibridizadas por insistentes processos de dominação cultural, religiosa e econômica. Nas obras de Said e Hatoum, o Oriente seria menos uma região ou um espaço geográfico definido do que produto de uma construção imperialista do Ocidente cuja ideologia central se configuraria no modo especial como a expansão colonial teria livre acesso ao locus de usurpação, podendo, desse modo, configurá-lo, reestruturá-lo de acordo com suas diretrizes culturais, mas, sobretudo, comerciais, enfim, uma dominação ampla e irrestrita, impossível de revogar.

Nas teses de Edward Said, consideramos importante o papel da institucionalização acadêmica na organização daquilo que se pode entender como a construção negativa do Oriente em oposição aos valores positivos - e positivistas - do Ocidente. O orientalismo acadêmico teria como função primordial espelhar certa visagem da organização da ação cultural sobre tudo aquilo que diz respeito à região oriental do mundo - como veremos mais adiante no exemplo que nos oferece Joseph Conrad num de seus textos mais densos, No coração das trevas, (2008) - tornando, assim, a autoridade sobre o que se entende afinal por Oriente não apenas plausível ou incontestável, mas, sobretudo, plenamente capaz de outorgar ao Ocidente qualquer tipo de ação sobre esse espaço de intervenção.

Em Edward Said e Milton Hatoum há, portanto, três modos de aproximá-los: primeiramente, o fato de que ambos se posicionam para além de uma geografia preestabelecida. São os entre-lugares que contam na identificação dos espaços liminares; em segundo lugar, Milton Hatoum sempre se preocupou em difundir a obra de Edward Said no Brasil, e por fim, e talvez o aspecto mais relevante desse contato, a relevância das teses orientalistas na formação intelectual e posteriormente na criação ficcional das narrativas pós-coloniais do escritor amazonense. Defende-se neste trabalho a ideia de que as obras de Milton Hatoum, na condição de uma profunda ironia do discurso dominante podem ser vinculadas ao chamado pós-colonialismo, pois representam uma leitura e uma continuação das questões problematizadas por Edward Said.

Se para ambos, o intelectual do século vinte apresenta-se como o estrangeiro, em Milton Hatoum há o diferencial da ordem de quem assume o lugar de fala, pois são principalmente seus personagens narradores, assumidamente deslocados da hegemonia da ordem 
social do ethos branco e civilizador do universo amazônico, que assumem a tarefa do testemunho, como assegura, por exemplo, Ademar Leão ao tratar da condição subalterna do narrador Nael, de Dois irmãos, que, segundo ele seria:

Eterno coadjuvante das ações que encena via linguagem, silenciado pela condição periférica que ocupa no plano familiar e social, cumpre ao narrador lançar mão de outras vozes que com a sua se amalgamam para tecer o fio que o conduz ao passado. Para tanto, faz-se ouvinte privilegiado dos fatos a partir de um espaço limiar de observação e testemunho mediado, obviamente, pela exclusão e pelo sofrimento - que lhe permite acompanhar atentamente os movimentos dos atores principais da saga familiar que dá corpo à sua narrativa. (LEÃO, 2005, p. 31)

A catástrofe assume um sentido histórico tanto para a produção romanesca de Milton Hatoum quanto para a filosofia da diferença de Edward Said. Trata-se de um olhar cuja perspectiva do passado também tem o poder de propor novas visagens para os dilemas no mundo pós-colonizado. Simbiose do que há de mais poroso, livre de um centro centrífugo e sem um começo capaz de reabilitar toda a noção de origem essencializante.

Edward Said (2011, p. 36) aborda a relação do passado no presente nos seguintes termos: “... A maneira como formulamos ou representamos o passado molda nossa compreensão e nossas percepções do presente." O que Edward Said parece alertar é para o perigo de não se inocular as manifestações do pensamento imperialista do passado na nossa própria maneira de enxergá-lo. Deve haver, desse modo, um complexo de forças múltiplas que delimitam o antigo imperialismo europeu, principalmente no século dezenove, cujo positivismo atávico foi elevado ao paroxismo, lançando assim, através de suas bases uma crítica ao capitalismo tardio e ao processo de globalização como seus frutos mais perenes.

O resultado, se pensado a partir da assunção da perspectiva que Gilles Deleuze e Félix Guattari (2012) na maneira como denominam esse pensamento, ou seja, como um "deslocamento nômade", o resultado configura-se na relação intersticial entre espaços lisos e espaços estriados, que significa dizer que se chega ao problema de dizer o "outro" como uma possibilidade de representação de alteridade apenas justificável por sua relação de proximidade com esse "outro" que, por sua condição de subalterno não pode dizer nada de si mesmo, pois ele vive num espaço liso. Eis o que, ao final deste primeiro capítulo tentar-se-á defender como uma das ações do horror: anular a credibilidade do colonizado, estriando o poder institucionalizado a ponto de destruir a memória daqueles que não têm voz ativa, o espaço estriado teria o poder de afetar a dimensão ética, política e cultural do aculturado.

O trabalho do intelectual das margens, portanto, teria de produzir outra cartografia através da representação memorialística capaz de não apenas se opor ao poder do Estado, mas, principalmente, subvertê-lo. Nesse sentido, Gilles Deleuze e Félix Guattari afirmam:

O Estado não confere um poder aos intelectuais ou aos conceptores; ao contrário, converte-os num órgão estreitamente dependente, cuja autonomia é ilusória, mas suficiente, contudo, para retirar toda potência àqueles que não fazem mais do que reproduzir ou executar. O que não impede que o Estado encontre dificuldades com esse corpo de intelectuais que ele mesmo engendrou, e que, no entanto,esgrime novas pretensões nomádicas e políticas. (DELEUZE \& GUATTARI, 2012, p. 37) 
É possível pensar que a natureza desse problema da representação dos excluídos do mundo se dá em nome da escritura, da noção problemática que a escritura representa, ou dito de outro modo, do logocentrismo que lhe encarna e da noção que Jacques Derrida $(2009$, p.4) the outorga como existência epistemológica autônoma do que habitualmente se compreende por escrita. Assim, quase tudo o que se diz sobre a experiência marginal no campo epistemológico procederia de um "fora", de uma maneira de pensar o papel da reconfiguração da memória a partir de certa noção de cultura híbrida, dos problemas sociais nessas regiões causados pelo colonialismo e pelo processo também marcante de descolonização.

Desconstruir envolve a árdua tarefa de fazer valer a passagem pelo espaço liminar, - o espaço liso de Gilles Deleuze - seja também a consolidação da memória como testemunha, pois a ficção chamada de pós-colonialista parece sugerir a possibilidade de se habitar, ao mesmo tempo, tanto a partir de "dentro" do relato como partindo do "fora", o deslocamento do testemunho para o espaço da ficção, do inaudito da experiência que, para Jacques Derrida (2002, p. 70) significa um campo que ultrapassa o limite da escritura como forma de testemunho. Seguindo a esteira de Jacques Derrida, Beatriz Sarlo (2007, p. 50) considera que o testemunho "é inseparável da autodesignação do sujeito que testemunha porque ele estava ali onde os fatos aconteceram [...]".

A teoria do orientalismo de Edward Said aproxima-se do plano temático-ficcional de Milton Hatoum de modo bastante regular no modo como ambos compreendem a dimensão quase sempre conflituosa da ação colonizadora. Os lugares marginalizados do mundo acabam funcionando segundo o condicionamento econômico-político imposto de "fora". O resultado na obra de Milton Hatoum é a reação da ficção sobre a natureza positiva da miscigenação no Brasil, pois, para as personagens desviantes de seus romances, o ethos branco traz consigo a marca da mentira, como é o caso de Yaqub, de Dois irmãos, que se muda para São Paulo, torna-se um próspero engenheiro, ao mesmo tempo em que não apenas passa a trair a família, mas se empenha também em destruí-la, até que, por fim, o leitor vê Yaqub aliando-se à Ditadura Militar.

Trata-se, portanto, de uma postura irônica do autor amazonense, centrando-se na defesa de uma ideia: "o ethos branco carrega a inerente marca da mentira" (SAID, 2011, p. 11). É possível perceber ao longo da narrativa o modo como a memória dos narradores processa os fatos que lhes são narrados ou que eles mesmos testemunham. O diferencial dessa perspectiva é que, na literatura, como nas outras formas de arte, a ficção efetiva-se como trabalho de articulação, cuja única filiação é sua relação com a linguagem e não exatamente com o "foi assim" do discurso oficial logocêntrico que precisa dizer a "verdade". Para Edward Said,

A cultura é uma espécie de teatro em que várias causas políticas e ideológicas se empenham mutuamente. Longe de ser um plácido reino de refinamento apolíneo, a cultura pode até ser um campo de batalha onde as causas se expõem à luz do dia e lutam entre si, deixando claro, por exemplo, que, dos estudantes americanos, franceses ou indianos ensinados a ler seus clássicos nacionais antes de lerem os outros, espera-se que amem e pertençam de maneira leal, e muitas vezes de maneira acrítica, às suas nações e tradições, enquanto denigrem e combatem as demais. (SAID, 2011, p. 12)

O modo como o sujeito se aproxima da cultura como um capital cultural não está isento, seguindo o raciocínio do filósofo palestino, de uma expropriação do modo como o 
"outro" pode representar a si mesmo. Mas surge, então, a questão que pode dar margem a essa linha de pensamento: por que é tão importante que o Ocidente se ocupe de ocidentalizar o resto do mundo? Essa questão pode passar por respostas diferentes e podem ser percebidas, como tentaremos demonstrar, interligadas.

A primeira hipótese é que se trata, principalmente, da dominação de um espaço geográfico alienígena cujo intuito é a exploração de seus bens materiais. Nesse caso, o contingente que ocuparia esse espaço teria como tarefa manter inalterada a posição central do poder. A segunda, mais sofisticada, atuaria de maneira sub-reptícia na tarefa de ratificar o que pode ser considerado pelo centro como culturalmente valioso para a posição da ação imperialista.

A imposição cultural, de acordo com nossa leitura de Edward Said, estaria de fato ligada à visão que Milton Hatoum elabora em suas narrativas e que deseja-se denominar, neste trabalho, como a experiência do horror nas margens do ocidente, a saber, que o retorno à cultura original do marginalizado não é apenas improvável, mas também perigoso e indesejável, porque é fruto de um pensamento igualmente ocupado com a noção de uma essência, como qualquer proposição que soe falsa seja qual for o ângulo que o problema apresente.

O horror dar-se-ia como um revés, quando aqueles que representam o mundo ocidental se defrontam com formas de resistência inesperadas, como é o caso da assimilação antropofágica. Isto significa dizer que há, em algum momento no processo de dominação, um esfacelamento gradual ou abrupto do projeto inicial, uma resistência autóctone inesperada, em que o dominador se vê expelido ou deslocado do próprio universo conceitual e territorial criado para servi-lo. Trata-se, portanto, de um estranhamento em face de uma inesperada reação daquele que seria, teoricamente, mais fraco. Esta, então, seria a gênese antevista por Joseph Conrad, sobretudo em seu romance mais emblemático, No coração das trevas (2008). Para Savian Filho (1996, p. 34), "o outro só é aceitável enquanto se submeter à imagem do todo que é introjetada; o outro que interroga e desestabiliza é abominável".

A desestabilização da noção de fronteira é outra marca importante em Edward Said e Milton Hatoum. Com as reticências que não indicam o limite para a demarcação do espaço geográfico, também a desarticulação das fronteiras culturais canônicas dá a entender que o tema do horror que tratamos neste trabalho pode ser percebido também como a sensação de não-pertencimento, ou o estar-entre [íon] - termo utilizado por Homi Bhabha (2013, p. 227) e também por Stuart Hall (2013, p. 453) para indicar menos um estágio do que um impasse dos temas em que a epistemologia tradicional se mostrasse ineficaz.

Além disso, o "estar-entre" também pode corresponder a um privilégio inesperado por aquele que não alcança as margens. O pensador marginal teria a vantagem, neste caso, de tornar efetivo o espaço privilegiado de uma forma de pensar mais apta a perceber as fraturas e os efeitos dos deslocamentos das questões primordiais do momento histórico. As diferenças culturais e o conceito de identidade cultural são espécies de campos de negociação e de intercâmbio. Representam a busca pela origem da identidade cultural. Para efeitos positivos, o deslocamento nômade produz certas práticas culturais que podem ser bastante úteis no processo antropofágico de resistência por parte do colonizado. A hibridização, por exemplo, põe em causa a crítica a conceitos como o de raça, classe social, gênero, questões que esperamos discutir a partir de nossa abordagem dos dois primeiros romances de Milton Hatoum.

O mundo colonizado é dominado pelo ponto de vista do "outro". Nesse sentido, há dominação e também desumanização das pessoas colonizadas; perda de identidade, desafios à fé, à linguagem e aos valores éticos e políticos do colonizado. No aspecto da identidade individual, nota-se a desumanização do "eu”, a inabilidade de proteção e suporte 
da família ancestral. Há, ainda, a dúvida em relação aos valores identitários do que se pode compreender como o "eu" que não consegue mais ligar-se a seus ancestrais e nem mesmo pode ligar-se aos colonizadores. É a perda de referência que liga esses habitantes do mundo "oriental".

Embora os empreendimentos teóricos recentes, denominados de pós-culturalismo, estejam necessariamente vinculados às necessidades e perspectivas epistemológicas e ontológicas muito específicas do mundo contemporâneo; e ainda que a tensão que a mantém, até certo ponto, distinta e paradoxal torne a enumeração de suas características algo sempre provisório e fluido e também alvo de contestações das mais diversas, no entanto, sem que a noção de ação pós-colonial e seu caráter eminentemente crítico em relação ao passado colonial, esteja posta em questão, não será possível compreender a complexidade das relações de poder entre história e ideologia, entre a tradição e o provisório.

\section{Considerações Finais}

Estudar o conjunto da obra de Milton Hatoum significa cartografar o modo particular como a região amazônica foi concomitantemente alvo de ações coloniais estrangeiras e nacionais. Os romances de Milton Hatoum perpassam um período histórico que vai do chamado "boom" da borracha no final do século dezenove até a ditadura militar no Brasil, que coincide com a criação da Zona Franca de Manaus e da Transamazônica.

Nos binômios memória e esquecimento percebem-se os temas responsáveis pela eclosão do horror: as políticas identitárias do mundo amazônico que emergem do centro do processo de colonização moderna costumeiramente falham no processo de interação de identidades múltiplas, o que gera o nomadismo e a hibridização cultural do colonizado, na virada do século dezenove para o século vinte. O que se perdeu ou o que foi excluído pelo relato oficial ganha novo contorno na escrita memorialística e não raro poética de Milton Hatoum.

Por meio da reescritura da História e, mediante o surgimento problemático de narradores que experimentam, no processo de ruínas dos valores civilizatórios nas margens do mundo, evidenciando que há sempre outra história dentro da História, quase sempre partindo do espaço mais familiar. Mas a mimese dos narradores dos romances de Milton Hatoum acaba subvertendo os valores dessa construção civilizatória por meio de uma ação mimético-irônica, que se percebe no modo como surgem, nos interstícios da narrativa, respostas mais complexas do que se poderia esperar de grupos sociais historicamente marginalizados que, através da ironia pós-colonizadora, dão o tom ao fracasso dos valores ocidentais nos trópicos.

\section{Referências}

BHABHA, H, K. O local da cultura. Belo Horizonte: Ed. UFMG,2013.

BIRMAN, Daniela. Entre-narrar: Relatos da fronteira em Milton Hatoum. 2007. Tese de Doutorado em Literatura Comparada apresentada ao Programa de Pós-Graduação em Ciência da Literatura, Faculdade de Letras, Universidade Federal do Rio de Janeiro. Data de acesso: 12/09/2017. 
BORDIEU, Pierre. In: Critérios, La Habana, n 25-28, enero 1989- diciembre 1990, pp. 20-42.

CONRAD, Joseph. No coração das trevas. São Paulo: Editora Abril Cultural, 2010.

CURY, M. Topografias da ficção de Milton Hatoum. In: RAVETTI, G, CURY, M, ÁVILA, M. (Orgs.). Topografias da cultura: representação, espaço e memória. Belo Horizonte: UFMG, 2009.

DELEUZE, G.; GUATTARI, F. Mil Platôs: capitalismo e esquizofrenia. 5 vols. São Paulo: Editora 34, 2011.

DELEUZE, G. GUATTARI, F. Mil Platôs: capitalismo e esquizofrenia. 5 vols. São Paulo: Editora 34, 2012.

DERRIDA, Jacques. A escritura e a diferença. 3.ed. São Paulo: Perspectiva, 2002.

DERRIDA, Jacques. A farmácia de Platão. São Paulo: Iluminuras, 2009.

FOUCAULT, M. Vigiar e punir: nascimento da prisão. Tradução de Raquel Ramalhete. Petrópolis, Rio de Janeiro: Vozes, 2012.

FRANCISCO, Dênis Leandro. A ficção em ruínas: Relato de um certo Oriente, de Milton Hatoum. 2007. Dissertação (Mestrado em Estudos Literários). Programa de Pós-Graduação em Letras: Estudos Literários. Faculdade de Letras da Universidade Federal de Minas Gerais. Disponível em: <http://www.miltonhatoum.com.br/wp-content/uploads/2010/09/ FRANCISCO-Denis-Leandro.-A-fic $\% \mathrm{C} 3 \% \mathrm{~A} 7 \% \mathrm{C} 3 \% \mathrm{~A} 3 \mathrm{o}-\mathrm{em}-\mathrm{ru} \% \mathrm{C} 3 \% \mathrm{ADnas}-$ Relato-de-um-certo-Oriente-de-Milton-Hatoum.pdf.>. Data de acesso:20/08/2016.

HADDOCK-LOBO, Rafael. A Desconstrução. Revista Cult, outubro, n¹95, 2014.

HALL, S. Da diáspora: identidades e mediações culturais. Belo Horizonte: Editora UFMG, 2013.

HATOUM, M. Relato de um certo Oriente. 2. ed. São Paulo: Companhia das Letras, 2014. HATOUM, Milton. "Escrever à margem da história". Entrevista concedida a Aida Hanania. 2001. Disponível em: <http://www.hottopos.com/collat6/milton1.htm>. Acesso em: 30/04/2019.

HATOUM, Milton. “Amazônia está à margem da história, diz escritor," O Estado de São Paulo, São Paulo, 8 Março, 1995, D 1.

LEÃO, Ademar. Dois Irmãos: um romance às margens do Negro. (2005). Dissertação de mestrado do Programa de Pós-Graduação em Letras. Universidade Federal de Santa Maria. UFSM, RS.

RIBEIRO, M. A. Os novos filhos da dor: Oriente e origem em Milton Hatoum. In: CRISTO, Maria da Luz Pinheiro de (Org.). Arquitetura da Memória: ensaios sobre os romances Relato de um certo Oriente, Dois Irmãos e Cinzas do Norte de Milton Hatoum. Valer, Oficina das Artes, Manaus, 2007.

SAID, Edward, W. Orientalismo: o oriente como invenção do Ocidente. São Paulo: Companhia das Letras, 2009.

SAID, Edward. W. Cultura e imperialismo. São Paulo: Companhia das Letras, 2011.

SARLO Beatriz. Tempo passado: cultura da memória e guinada subjetiva. São Paulo: Companhia das Letras, 2007.

SAVIAN, J.F. A cultura do exílio na narrativa contemporânea. In: Revista Cult, n¹96, nov. 2015.

SOUZA, Márcio. Expressão Amazonense: do colonialismo ao neocolonialismo. 2. ed. Manaus: Valer, 1977.

Recebido em: 10/03/2019; Aceito em: 24/04/2019 